\title{
Incidence of urinary extravasation and rate of ureteral stenting after high-grade renal trauma in adults: a meta-analysis
}

\author{
Sorena Keihani ${ }^{1}$, Ross E. Anderson ${ }^{1}$, Michelle Fiander ${ }^{2}$, Mary M. McFarland ${ }^{3}$, Gregory J. Stoddard ${ }^{4}$, \\ James M. Hotaling ${ }^{1}$, Jeremy B. Myers ${ }^{1}$ \\ ${ }^{1}$ Division of Urology, Department of Surgery, ${ }^{2}$ College of Pharmacy, ${ }^{3}$ Eccles Health Sciences Library, ${ }^{4}$ Division of Epidemiology, Department of \\ Internal Medicine, University of Utah, Salt Lake City, Utah, USA \\ Contributions: (I) Conception and design: S Keihani, JB Myers, M Fiander, MM McFarland; (II) Administrative support: M Fiander, MM McFarland; \\ (III) Provision of study materials or patients: S Keihani, M Fiander, MM McFarland; (IV) Collection and assembly of data: S Keihani, RE Anderson, \\ M Fiander, MM McFarland; (V) Data analysis and interpretation: S Keihani, GJ Stoddard; (VI) Manuscript writing: All authors; (VII) Final approval \\ of manuscript: All authors. \\ Correspondence to: Sorena Keihani, MD. Division of Urology, Department of Surgery, University of Utah School of Medicine, 30 North 1900 East, \\ Salt Lake City, UT 84132, USA. Email: sorena.keihani@hsc.utah.edu.
}

\begin{abstract}
Background: Collecting system injury and urinary extravasation is an important yet understudied aspect of renal trauma. We aimed to examine the incidence of urinary extravasation and also the rates of ureteral stenting after high-grade renal trauma (HGRT) in adults.

Methods: A search strategy was developed to search Ovid Medline, Embase, CINAHL, and Cochrane Library. Two reviewers screened titles and abstracts, followed by full-text review of the relevant publications. Studies were included if they indicated the number of patients with HGRT [the American Association for the Surgery of Trauma (AAST) grades III-IV or equivalents] and number of patients with urinary extravasation. A descriptive meta-analysis of binary proportions was performed with random-effects model to calculate the incidence of urinary extravasation and rates of ureteral stenting.

Results: After screening, 24 and 20 studies were included for calculating urinary extravasation and stenting rates, respectively. Most studies involved blunt injury and were retrospective single-center case series. Incidence of urinary extravasation was 29\% (95\% CI: 17-42\%) after HGRT (grade III-V), and 51\% (95\% CI: 38-64\%) when only grade IV-V injuries were combined. Overall, 29\% (95\% CI: 22-36\%) of patients with urinary extravasation underwent ureteral stenting.

Conclusions: Approximately 30\% of patients with HGRT are diagnosed with urinary extravasation and $29 \%$ of those with urinary extravasation undergo ureteral stenting. Understanding the rate of urinary extravasation and interventions is the first step in creating a prospective trial designed to demonstrate when ureteral stenting and aggressive management of urinary extravasation is needed.
\end{abstract}

Keywords: Renal trauma; renal injury grading; wounds and injuries; urinary extravasation; meta-analysis, ureteral stent

Submitted Apr 04, 2018. Accepted for publication Apr 09, 2018.

doi: 10.21037/tau.2018.04.13

View this article at: http://dx.doi.org/10.21037/tau.2018.04.13

\section{Introduction}

Traumatic renal injuries are comprised of a spectrum of parenchymal, vascular, and renal pelvic lacerations. An important aspect of renal trauma is the diagnosis and management of urinary extravasation. Urinary extravasation may be a relative indication for intervention and a reason for failure of conservative management after high-grade renal trauma (HGRT) (1). A timely and precise diagnosis of urinary extravasation, and proper intervention, can potentially minimize complications after HGRT.

The majority of renal trauma literature is focused on parenchymal lacerations and the risk of bleeding. 
Despite the importance of properly diagnosing urinary extravasation, very little is known about the true incidence of urinary extravasation after HGRT (2). It is believed that most cases of minor urinary extravasation will heal spontaneously; ureteral stenting is commonly used when an intervention is needed or if complications arise. However, the rates of stenting, as well as its indications, are also not well defined. We aimed to perform a review and pool data from the published literature, to examine the incidence of urinary extravasation after adult HGRT and also the rates of ureteral stenting in management of urinary extravasation.

\section{Methods}

A scoping review design was used to map the existing literature and clarify concepts related to incidence and management of urinary extravasation using an a priori protocol to define our objectives and methods as previously described (3). Full details of the methods used are available as supplementary material.

Criteria for inclusion of studies were: adult renal trauma patients, studies published in 1989 or later [after the publication of the current American Association for the Surgery of Trauma (AAST) grading system], and quantification of number of patients with HGRT (using AAST grading or equivalents), number with urinary extravasation, and number who underwent ureteral stenting.

We used the AAST grading for classification of renal injuries (4). HGRT was defined as AAST grades III-V or equivalents if converting to AAST grading was possible. Similarly, grades III-V renal injuries according to the proposed revisions to the original AAST grading system were considered HGRT (5). We also converted the Japanese Association for the Surgery of Trauma (JAST) classifications to the corresponding AAST grades IV and V based on the scales suggested by Nishizawa et al. (6). We only calculated rates for ureteral stenting, because other procedures such as nephrostomy tube, peri-renal drain placement, and open surgeries were inconsistently reported, making it impossible to calculate meaningful intervention rates for these other procedures.

A sensitive search strategy was developed for Ovid Medline, peer-reviewed, then translated to Embase, CINAHL, and Cochrane Library databases. No language or study design filter was used. EndNote X7 software (Clarivate Analytics, Boston, MA, USA), was used to manage and deduplicate references.

Title, abstract and full-text screening were conducted independently by two reviewers with disagreements resolved by consensus or a third reviewer. A data extraction form was developed to collect the information including: full reference details, study design and duration, mechanism of trauma, total number of participants, number of patients with HGRT, grades of injury, number of patients with urinary extravasation, and number of patients treated with ureteral stenting. Data extraction was conducted by both reviewers.

Incidence of urinary extravasation was calculated based on the extracted values for each study. The rates of urinary extravasation were reported differently based upon studies' inclusion criteria and whether studies reported urinary extravasation rates in populations of grades III-V, IV-only, or IV-V. Separate and detailed rates were extracted from each study when the information was available. Rate of ureteral stenting was calculated in patients diagnosed with urinary extravasation. A meta-analysis of single sample binary proportions was performed using a random-effects model to pool the estimates and calculate confidence intervals (CIs) using STATA-15 statistical software (Stata corp., College Station, TX, USA).

\section{Results}

Figure 1 shows the screening and study selection steps according to the Preferred Reporting Items for Systematic Reviews and Meta-Analyses (PRISMA) guidelines (7). A total of 27 studies were included for full data extraction. Most studies were retrospective and mostly involved blunt renal trauma. Twenty-four studies contained information, which could be used to calculate urinary extravasation rates (2,6,8-29). A total of 20 studies contained enough information to calculate ureteral stenting rates for urinary extravasation (2,8,9,11-15,18-21,23-25,29-33). Three studies were only used to calculate stenting rates without containing information to calculate incidence of urinary extravasation (30-32).

\section{Incidence of urinary extravasation}

Of the 24 studies that were included for calculating urinary extravasation rates, only 4 were prospective $(8,13,20,23)$; three of them from the same center and with some overlap in data $(13,20,23)$. Two of the 24 included studies, which met our inclusion criteria, are meeting abstracts with no published manuscript $(17,24)$. Seventeen studies included data on only blunt renal trauma, 6 on both blunt and 


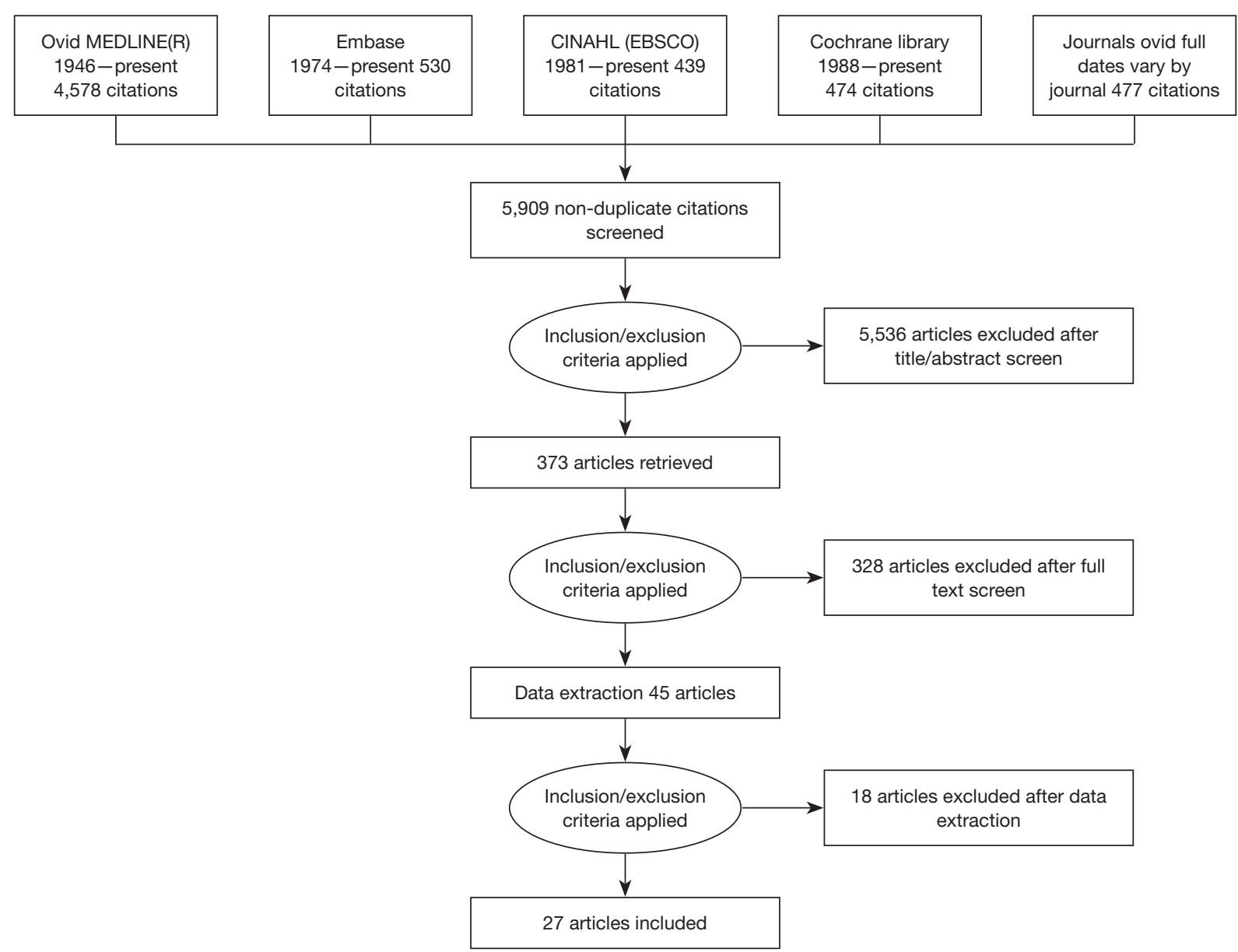

Figure 1 Screening and selection of articles (PRISMA flow diagram). PRISMA, Preferred Reporting Items for Systematic Reviews and Meta-Analyses

penetrating injuries $(2,8,9,11,21,28)$, and 1 on penetrating injuries only (17) (Table 1).

In 5 studies $(9,15,18,20,22)$, rates of urinary extravasation were only available for patients with grade IV injuries and in 6 studies $(6,10,12,13,19,26)$ this rate was only available for grade IV-V injuries combined. The other studies included sufficient detail to calculate rates for different combinations of renal injury grades (Table 1). Incidence of urinary extravasation was $29 \%$ (95\% CI: $17-42 \%$ ) when all grade III-V injuries were combined, $74 \%$ (95\%: CI: $61-85 \%)$ when only grade IV renal injuries were reported, and $51 \%$ (95\% CI: 38-64\%) when grades IV and V injuries were combined (Figure $2 A, B, C$ ).

\section{Rate of ureteral stenting for urinary extravasation}

A total of 20 studies contained information to calculate rates of ureteral stenting for urinary extravasation. Five studies $(18,20,23,29,33)$ were not included in the meta-analysis for stenting rates because of data overlap with other studies included in the analysis $(9,13,32)$. Table 2 summarizes the 15 studies included for calculating rate of ureteral stenting for urinary extravasation. Overall, 29\% (95\% CI: $22-36 \%$ ) of patients with urinary extravasation received ureteral stenting either immediately or in a delayed fashion (Figure 3).

\section{Discussion}

Most estimations on the incidence of urinary extravasation and ureteral stenting after renal trauma are inferred from few studies with small sample sizes. This study pools the results from multiple studies and the findings provide a more comprehensive estimate for urinary extravasation and ureteral stenting. In our meta-analysis, urinary extravasation 


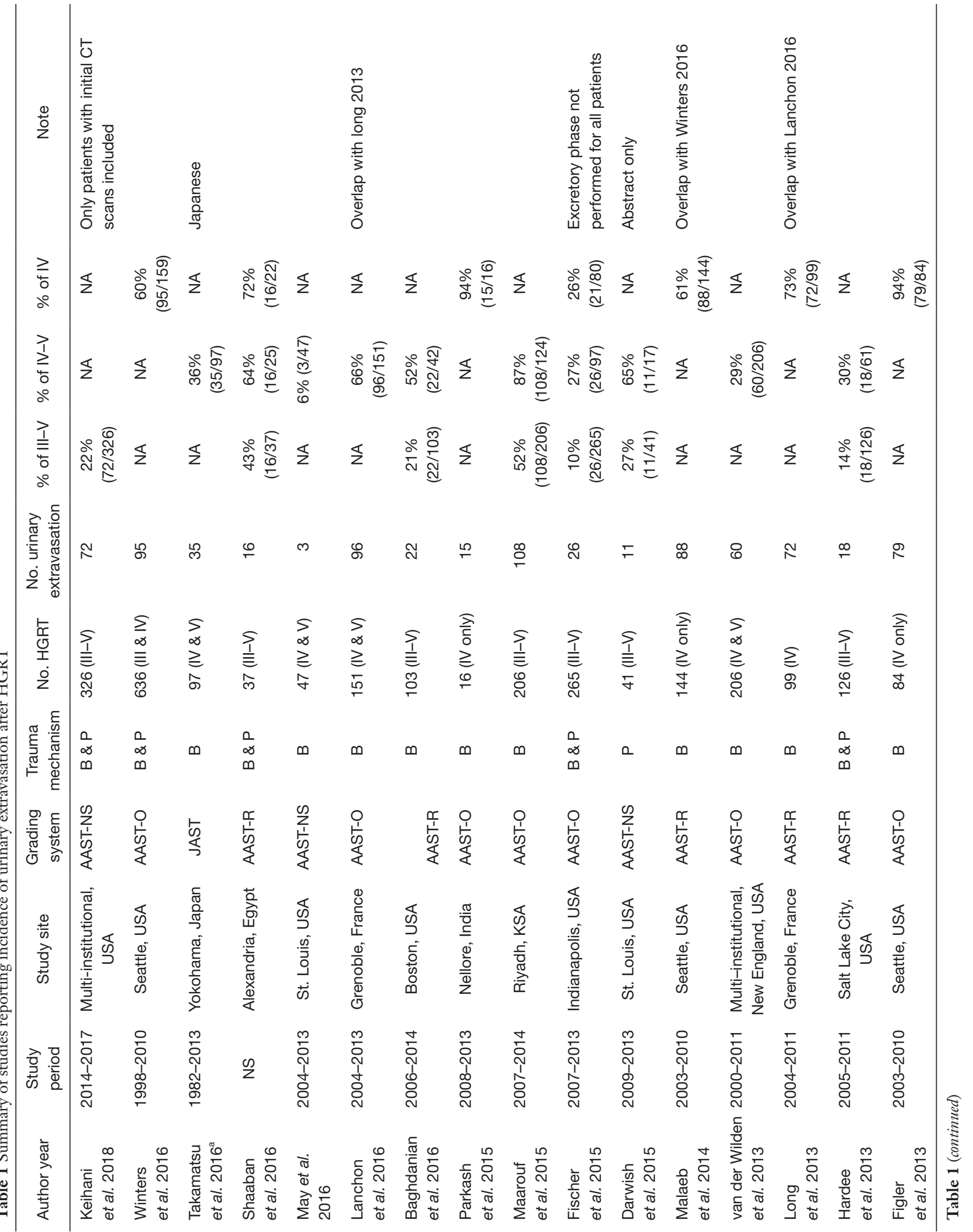




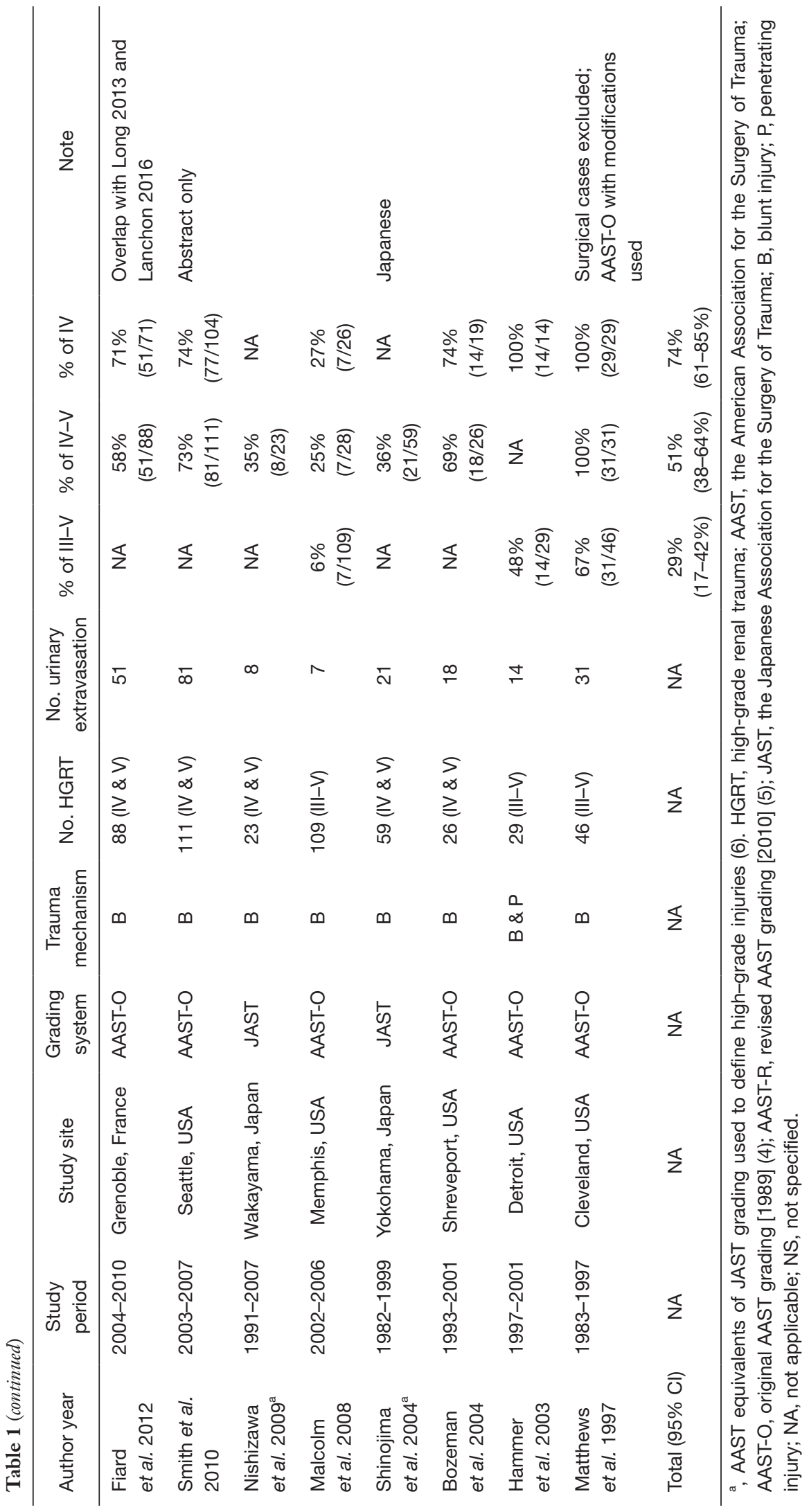




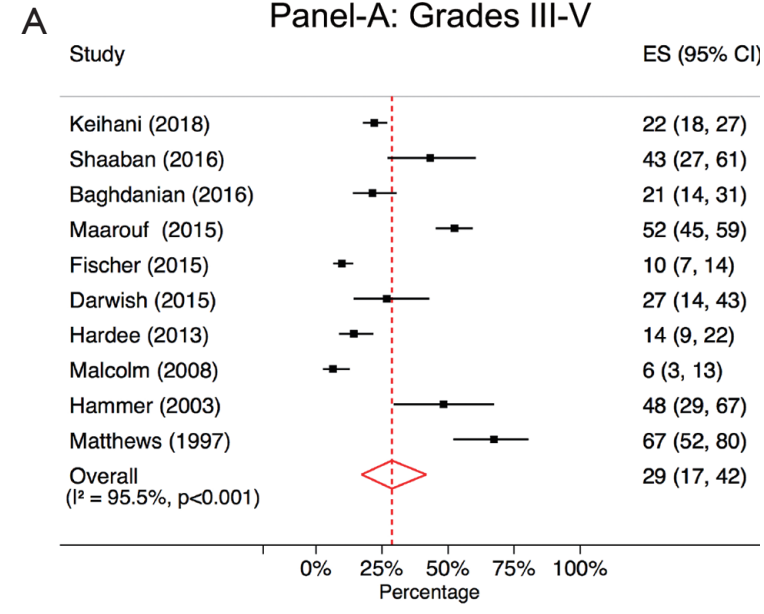

B

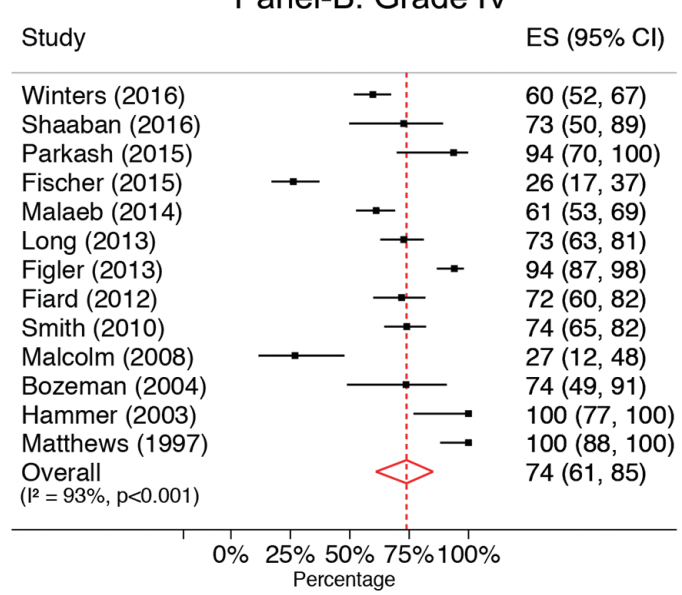

C

\begin{tabular}{|c|c|c|}
\hline \multicolumn{3}{|c|}{ Panel-C: Grades IV-V } \\
\hline Study & & ES $(95 \% \mathrm{Cl})$ \\
\hline $\begin{array}{l}\text { Takamatsu (2016) } \\
\text { Shaaban (2016) } \\
\text { May (2016) } \\
\text { Lanchon (2016) } \\
\text { Baghdanian (2016) } \\
\text { Maarouf }(2015) \\
\text { Fischer (2015) } \\
\text { Darwish }(2015) \\
\text { van der Wilden (2013) } \\
\text { Hardee (2013) } \\
\text { Fiard (2012) } \\
\text { Smith (2010) } \\
\text { Nishizawa (2009) } \\
\text { Malcolm (2008) } \\
\text { Shinojima (2004) } \\
\text { Bozeman }(2004) \\
\text { Matthews }(1997) \\
\text { Overall } \\
\left(\left.\right|^{2}=95 \%, \mathrm{p}<0.001\right)\end{array}$ & $\rightarrow$ & $\begin{array}{l}36(27,46) \\
64(43,82) \\
6(1,18) \\
64(55,71) \\
52(36,68) \\
87(80,92) \\
27(18,37) \\
65(38,86) \\
29(23,36) \\
30(19,43) \\
58(47,68) \\
73(64,81) \\
35(16,57) \\
25(11,45) \\
36(24,49) \\
69(48,86) \\
100(89,100) \\
51(38,64)\end{array}$ \\
\hline
\end{tabular}

Figure 2 Incidence of urinary extravasation after HGRT for AAST grades III-V (A), IV-only (B), and IV-V (C). HGRT, highgrade renal trauma; AAST, American Association for the Surgery of Trauma; ES, estimate. was diagnosed in about $30 \%$ of HGRT (defined as AAST grade III to V). This rate was naturally higher (51\%) when only grade IV and V injuries were considered. In our pooled analysis, about $29 \%$ of patients with urinary extravasation after HGRT underwent ureteral stenting.

True incidence of urinary extravasation after HGRT is difficult to estimate due to the limitations of the current evidence. Studies are usually small and from single institutions, and the definitions and grading systems used in different studies are inconsistent. Accurate diagnosis of urinary extravasation requires obtaining abdomen/pelvis CT scans with a delayed excretory phase as recommended by the American Urological Association (AUA) urotrauma guidelines (34). Many of the patients who present in shock or undergo immediate laparotomy do not have a pre-operative CT scan available. Additionally, excretory phase images are not always obtained in trauma patients as the compliance with these imaging recommendations are variable even in level-1 trauma centers (21). As a result, we observed a wide range for incidence of urinary extravasation between studies in our analysis (e.g., range of $6.5-67 \%$ for grade III-V injuries). It could be argued that pooling the results for grade III-V injuries add little additional information as by definition grade III injuries do not include collecting system injuries, and presence of urinary extravasation would upgrade the injury to grade IV. However, in real practice, many patients do not undergo initial delayed phase imaging-which is necessary for accurate grading - and some injuries are initially classified as grade III until complications arise or adequate imaging is performed. Thus, rates of urinary extravasation after HGRT (which includes grade III) provides a better estimation of the prevalence and burden of urinary extravasation after HGRT and calls for prospective trials to study optimal management of this condition.

When considering grade IV injuries, we found a $74 \%$ rate of urinary extravasation. Renal injuries are graded as IV either when there is a large laceration leading to collecting system injuries or when specific vascular injuries are present. As expected, most grade IVs are based on the hallmark of collecting system laceration; however, variations in grading definitions can lead to over- or under-estimation of the proportion of grade IV patients with urinary extravasation. For example, in some studies, the authors used adaptations of the AAST grading by dropping the vascular component of grade IV classification (29). This essentially makes all grade IV injuries collecting system lacerations (i.e., 100\% rate of urinary extravasation for grade IV). However, based 
Table 2 Summary of studies reporting rates of ureteral stenting for urinary extravasation after HGRT

\begin{tabular}{|c|c|c|c|c|}
\hline Author year & $\begin{array}{l}\text { Trauma } \\
\text { mechanism }\end{array}$ & $\begin{array}{l}\text { No. urinary } \\
\text { extravasation }\end{array}$ & $\begin{array}{l}\text { No. stented } \\
(\%)\end{array}$ & Comment \\
\hline Keihani et al. 2018 & $B \& P$ & 72 & $17(24 \%)$ & $\begin{array}{l}\text { Multi-institutional data from the Genito-Urinary Trauma Study Group; only } \\
\text { patients with CT scans available for review were included in the analysis }\end{array}$ \\
\hline Winters et al. 2016 & $B \& P$ & 95 & 27 (28\%) & $\begin{array}{l}\text { Routine follow-up CT scan at } 48 \mathrm{~h} \text { and prophylactic stenting if } \\
\text { persistent or worsening leak. Grade V injuries were excluded }\end{array}$ \\
\hline May et al. 2016 & $\mathrm{~B}$ & 3 & 1 (33\%) & \\
\hline Lanchon et al. 2016 & B & 96 & $29(30 \%)$ & $\begin{array}{l}\text { Retrograde ureteral stent placement was performed secondarily in } \\
\text { patients with symptomatic ureteral clot obstruction or significant urine } \\
\text { leakage on subsequent CT }\end{array}$ \\
\hline $\begin{array}{l}\text { Baghdanian } \\
\text { et al. } 2016\end{array}$ & B & 22 & $11(50 \%)$ & $\begin{array}{l}\text { High rates of delayed diagnosis and intervention for urinary } \\
\text { extravasation ( } 50 \% \text { missed at the initial imaging) }\end{array}$ \\
\hline Fischer et al. 2015 & $B \& P$ & 26 & $12(46 \%)$ & $\begin{array}{l}\text { About half of the patients did not undergo excretory phase imaging; } \\
\text { number of urinary extravasation may be underestimated }\end{array}$ \\
\hline $\begin{array}{l}\text { Van der Wilden } \\
\text { et al. } 2013\end{array}$ & B & 60 & $24(40 \%)$ & $\begin{array}{l}\text { Multi-institutional data; about half the stentings were performed for } \\
\text { delayed complications }\end{array}$ \\
\hline Hardee et al. 2013 & $B \& P$ & 21 & $9(43 \%)$ & $\begin{array}{l}\text { Includes three ureteral injuries; delayed urinary extravasation identified } \\
\text { in } 7 \text { patients without initial excretory phase imaging }\end{array}$ \\
\hline Smith et al. 2010 & B & 81 & $16(20 \%)$ & \\
\hline Haas et al. 1998 & B & 31 & $5(16 \%)$ & $\begin{array}{l}\text { Management included bed rest until resolution of gross hematuria, } \\
\text { broad spectrum antibiotics, and close follow-up with appropriate } \\
\text { radiographic studies }\end{array}$ \\
\hline Total $(95 \% \mathrm{Cl})$ & NA & NA & $\begin{array}{c}28 \% \\
(21-36 \%)\end{array}$ & \\
\hline
\end{tabular}

HGRT, high-grade renal trauma; B, blunt injury; P, penetrating injury.

on the proposed revised AAST classification (5), about $60 \%$ of grade IV injuries are collecting system lacerations while another $40 \%$ are segmental vascular injuries (9). Thus, a grade IV injury is not equivalent to having urinary extravasation and reporting injury specifics is required for a better understanding of injury patterns and management protocols.

Guidelines for management of urinary extravasation after renal injury are not well established. It is widely believed that most cases of urinary extravasation - as high as $76 \%$ to $90 \%$-will heal spontaneously and without any intervention (29-31). Endoscopic ureteral stenting has 


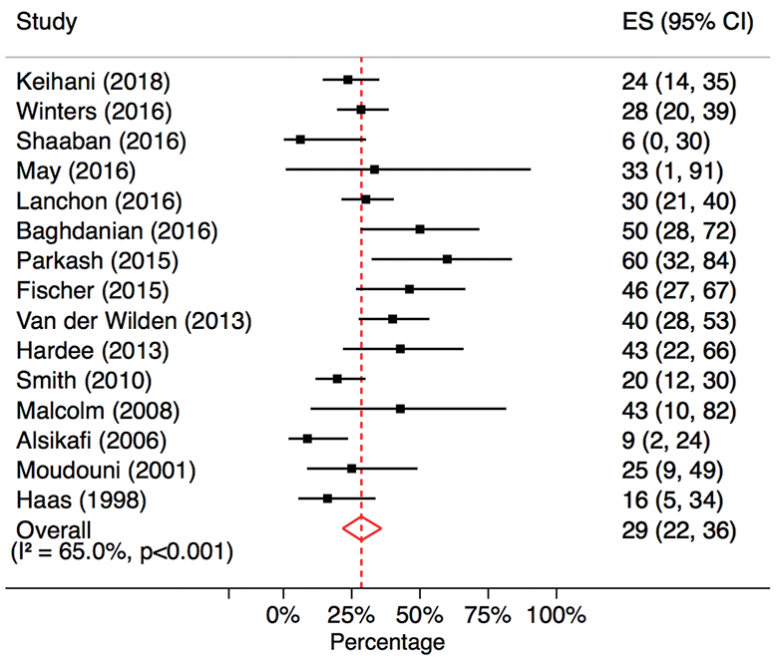

Figure 3 Rates of ureteral stenting after HGRT. HGRT, highgrade renal trauma; ES, estimate.

been recommended for cases of persistent or progressive extravasation, which was estimated to occur in $13-26 \%$ of patients with urinary extravasation (35). The observed rates of stenting in our meta-analysis (29\%, 95\% CI: 22-36\%) suggests higher rates of ureteral stent use for urinary extravasation; however, it remains unknown in what fraction of patients ureteral stenting could be avoided and how many patients actually underwent stenting due to complications. The variation in ureteral stenting rates largely depends upon clinicians' beliefs about the best management for urinary extravasation and there are likely significant variations in management protocols at different centers (21). For example, in a survey by Yeung et al., trauma surgeons were more likely to opt for early stenting for urinary extravasation, while urologists had a higher threshold for intervention and usually relied on follow-up imaging and clinical symptoms (36).

Several theoretical concerns arise with overuse of ureteral stents. One concern is that endoscopic procedures may potentially contaminate perinephric collections and increase the risk of infected hematoma or urinoma. Also, ureteral stents are generally used by urologists to bypass obstructions such as a ureteral stricture or calculi. While blood clots may obstruct the kidney and encourage urinary extravasation, in many circumstance, there is an axiomatic but potentially false belief that a stent will increase urinary flow out of the kidney. In fact, the ureter is designed to maximize flow with its peristaltic action and may be far better at emptying the kidney compared to a stent in place (37).
This study has several limitations. There is obvious selection bias in the included studies; i.e., emergency operative cases and those that did not have appropriate imaging studies were excluded from most studies which can lead to underestimation of urinary extravasation rates, as these patients usually have more severe injuries. Information on percutaneous nephrostomy was not provided in the screened articles, thus the actual rates of renal drainage for urinary extravasation may be higher. Additionally, most included studies are from high-volume level-1 trauma centers which are known to use expectant management at a higher rate compared to lower tier trauma center. Thus, the $29 \%$ rate of ureteral stenting might be an underestimation. However, better understanding of this incidence is important for urologists treating HGRT and highlights the importance of prospective trials to study management of urinary extravasation. Another limitation is that the pooled results, in our study, span decades of care during which diagnosis and management of renal trauma has considerably changed; so some rates from older studies may not be applicable to current management of urinary extravasation. Last but not least, the protocols and indications for ureteral stenting are not well-defined in urotrauma guidelines so physician and center preferences no doubt significantly affected the rates in different studies.

\section{Conclusions}

The incidence of urinary extravasation after high grade renal trauma was $29 \%$ (95\% CI: $17-42 \%$ ) for grade III$\mathrm{V}$ injuries, 51\% (95\% CI: 38-64\%) for grades IV and V, and $74 \%$ (95\% CI: $61-85 \%$ ) for grade IV renal injuries. The rate of ureteral stenting in patients with urinary extravasation was $29 \%$ (95\% CI: $22-36 \%$ ). Understanding these rates are essential as a first step for designing prospective trials to evaluate the utility and timing of ureteral stenting in the treatment of urinary extravasation after renal trauma.

\section{Acknowledgements}

Funding: This investigation was supported by the University of Utah Population Health Research (PHR) Foundation, with funding in part from the National Center for Research Resources and the National Center for Advancing Translational Sciences, National Institutes of Health, through Grant 5UL1TR001067-05 (formerly 8UL1TR000105 and UL1RR025764). 


\section{Footnote}

Conflicts of Interest: The authors have no conflicts of interest to declare.

\section{References}

1. Santucci RA, Fisher MB. The literature increasingly supports expectant (conservative) management of renal trauma--a systematic review. J Trauma 2005;59:493-503.

2. Fischer W, Wanaselja A, Steenburg SD. JOURNAL CLUB: Incidence of Urinary Leak and Diagnostic Yield of Excretory Phase CT in the Setting of Renal Trauma. AJR Am J Roentgenol 2015;204:1168-72; quiz 73.

3. Peters MD, Godfrey CM, Khalil H, et al. Guidance for conducting systematic scoping reviews. Int J Evid Based Healthc 2015;13:141-6.

4. Moore EE, Shackford SR, Pachter HL, et al. Organ injury scaling: spleen, liver, and kidney. J Trauma 1989;29:1664-6.

5. Buckley JC, McAninch JW. Revision of current American Association for the Surgery of Trauma Renal Injury grading system. J Trauma 2011;70:35-7.

6. Nishizawa S, Mori T, Shintani Y, et al. Applicability of blunt renal trauma classification of Japanese Association for the Surgery of Trauma (JAST). Int J Urol 2009;16:862-7.

7. Moher D, Liberati A, Tetzlaff J, et al. Preferred reporting items for systematic reviews and meta-analyses: the PRISMA statement. Int J Surg 2010;8:336-41.

8. Keihani S, Xu Y, Presson AP, et al. Contemporary Management of High-Grade Renal Trauma: Results from the American Association for the Surgery of Trauma (Aast) Genitourinary Trauma Study. J Trauma Acute Care Surg 2018;84:418-25.

9. Winters B, Wessells H, Voelzke BB. Readmission after treatment of Grade 3 and 4 renal injuries at a Level I trauma center: Statewide assessment using the Comprehensive Hospital Abstract Reporting System. J Trauma Acute Care Surg 2016;80:466-71.

10. Takamatsu K, Nakajima $Y$, Ishida $M$, et al. Predictive factors of the initial treatment for 207 blunt renal trauma cases based on the classification for renal injury of japanese association for the surgery of trauma 2008's version. Nippon Hinyokika Gakkai Zasshi 2016;107:13-20.

11. Shaaban MS, Khattab HMB, El-Sirafy MNI, et al. Multidetector CT assessment of traumatic renal lesions. Alex J Med 2016;52:173-84.

12. May AM, Darwish O, Dang B, et al. Successful Nonoperative Management of High-Grade Blunt Renal
Injuries. Adv Urol 2016;2016:3568076.

13. Lanchon C, Fiard G, Arnoux V, et al. High Grade Blunt Renal Trauma: Predictors of Surgery and Long-Term Outcomes of Conservative Management. A Prospective Single Center Study. J Urol 2016;195:106-11.

14. Baghdanian AH, Baghdanian AA, Armetta A, et al. Utility of MDCT findings in predicting patient management outcomes in renal trauma. Emerg Radiol 2017;24:263-72.

15. Prakash SV, Mohan CG, Reddy VBG, et al. Salvageability of kidney in Grade IV renal trauma by minimally invasive treatment methods: A tertiary care single institute experience. J Emerg Trauma Shock 2015;8:16-20.

16. Maarouf AM, Ahmed AF, Shalaby E, et al. Factors predicting the outcome of non-operative management of high-grade blunt renal trauma. Afr J Urol 2015;21:44-51.

17. Darwish O, Dang B, Adsul P, et al. Penetrating renal injuries: Feasibility of nonoperative management. J Urol 2015;193:e212.

18. Malaeb B, Figler B, Wessells H, et al. Should blunt segmental vascular renal injuries be considered an American Association for the Surgery of Trauma Grade 4 renal injury? J Trauma Acute Care Surg 2014;76:484-7.

19. van der Wilden GM, Velmahos GC, Joseph DK, et al. Successful nonoperative management of the most severe blunt renal injuries: a multicenter study of the research consortium of New England Centers for Trauma. JAMA Surg 2013;148:924-31.

20. Long JA, Fiard G, Descotes JL, et al. High-grade renal injury: non-operative management of urinary extravasation and prediction of long-term outcomes. BJU Int 2013;111:E249-55.

21. Hardee MJ, Lowrance W, Stevens MH, et al. Process improvement in trauma: compliance with recommended imaging evaluation in the diagnosis of high-grade renal injuries. J Trauma Acute Care Surg 2013;74:558-62.

22. Figler BD, Malaeb BS, Voelzke B, et al. External validation of a substratification of the American Association for the Surgery of Trauma renal injury scale for grade 4 injuries. J Am Coll Surg 2013;217:924-8.

23. Fiard G, Rambeaud JJ, Descotes JL, et al. Long-term renal function assessment with dimercapto-succinic acid scintigraphy after conservative treatment of major renal trauma. J Urol 2012;187:1306-9.

24. Smith T, Wessells H, Voelzke B. Contemporary evaluation and management of 111 high-grade blunt renal injuries. J Urol 2010;183:e28-e9.

25. Malcolm JB, Derweesh IH, Mehrazin R, et al. Nonoperative management of blunt renal trauma: is 
routine early follow-up imaging necessary? BMC Urol 2008;8:11.

26. Shinojima T, Nakajima Y, Kitano M, et al. Evaluation of 115 consecutive patients with blunt renal trauma by using the classification for renal injury of Japanese Association for the Surgery of Trauma. Nippon Hinyokika Gakkai Zasshi 2004;95:783-91.

27. Bozeman C, Carver B, Zabari G, et al. Selective operative management of major blunt renal trauma. J Trauma 2004;57:305-9.

28. Hammer CC, Santucci RA. Effect of an institutional policy of nonoperative treatment of grades I to IV renal injuries. J Urol 2003;169:1751-3.

29. Matthews LA, Smith EM, Spirnak JP. Nonoperative treatment of major blunt renal lacerations with urinary extravasation. J Urol 1997;157:2056-8.

30. Alsikafi NF, McAninch JW, Elliott SP, et al. Nonoperative management outcomes of isolated urinary extravasation following renal lacerations due to external trauma. J Urol 2006;176:2494-7.

31. Moudouni SM, Patard JJ, Manunta A, et al. A conservative

Cite this article as: Keihani S, Anderson RE, Fiander M, McFarland MM, Stoddard GJ, Hotaling JM, Myers JB. Incidence of urinary extravasation and rate of ureteral stenting after high-grade renal trauma in adults: a meta-analysis. Transl Androl Urol 2018;7(Suppl 2):S169-S178. doi: 10.21037/ tau.2018.04.13 approach to major blunt renal lacerations with urinary extravasation and devitalized renal segments. BJU Int 2001;87:290-4.

32. Haas CA, Reigle MD, Selzman AA, et al. Use of ureteral stents in the management of major renal trauma with urinary extravasation: is there a role? J Endourol 1998;12:545-9.

33. Matthews LA, Spirnak JP. The nonoperative approach to major blunt renal trauma. Semin Urol 1995;13:77-82.

34. Morey AF, Brandes S, Dugi DD 3rd, et al. Urotrauma: AUA guideline. J Urol 2014;192:327-35.

35. Al-Qudah HS, Santucci RA. Complications of renal trauma. Urol Clin North Am 2006;33:41-53, vi.

36. Yeung L, Brandes S. Contemporary management of renal trauma: Differences between urologists and trauma surgeons. J Urol 2011;185:e37.

37. Venkatesh R, Landman J, Minor SD, et al. Impact of a double-pigtail stent on ureteral peristalsis in the porcine model: initial studies using a novel implantable magnetic sensor. J Endourol 2005;19:170-6. 


\section{Methodology}

We referred to Scoping Review (ScR) methodology per Arksey and O'Malley and The Joanna Briggs Institute Methodology for Scoping Reviews for this investigation $(3,38)$. As a method of evidence synthesis, the ScR is useful to identify and characterize (or map) a body of literature rather than answer a focused question of effectivenessas do Systematic Reviews of effectiveness; and unlike the Systematic Reviews where all criteria and methods are specified a priori, the ScR allows for post-hoc decision making. Additionally, scoping reviews do not typically include quality assessment of the included studies. Given that the incidence of urinary extravasation is poorly reported, diagnosis is difficult, and management is not supported by evidence-based guidelines, the ScR approach suited the intention of this review - to provide a limited meta-analysis and narrative synthesis of incidence, diagnosis and management of urinary extravasation.

\section{Inclusion criteria}

All of the following criteria were required for inclusion:

* Adults 16 years and older;

* High grade renal trauma defined using the American Association for the Surgery of Trauma (AAST) grading (4) as grades III-V (or equivalent);

* Patients with diagnosed urinary extravasation (for calculation of incidence of urinary extravasation after high-grade renal trauma) or patients undergoing ureteral stenting for urinary extravasation (for calculation of rates of ureteral stenting after diagnosis of urinary extravasation);

* Published 1989 or later [a post-literature search decision based on the publication date of the AAST grading system (4)].

\section{Literature search}

Due to a lack of controlled vocabulary or keyword references (e.g., Medline $\mathrm{MeSH}$ terms) for urinary extravasation in the literature, a sensitive search strategy, focused on renal trauma was used. A strategy was developed for OVID Medline, peer reviewed and then translated for the following databases: CINAHL (Ebsco), Cochrane Library (Wiley), and Embase. com. We also ran a keyword search in a collection of full-text journals via OVID, and checked reference lists of included or related studies. We used no language, methodological (study design), or date limits for the initial search. EndNote X7 software (Clarivate Analytics, Boston, MA, USA) was used to manage and deduplicate references.

\section{Study selection}

Title, abstract and full-text screening were conducted independently by two reviewers with disagreements resolved by consensus or a third reviewer. A PRISMA flow diagram on the screening and inclusion steps is available in the manuscript (Figure 1).

\section{Data extraction}

Data extraction was conducted by both reviewers. A data extraction form was developed in Excel and is available at the end of this document. When multiple studies from the same center with data overlap were available, we used data from the most recent study and used other reports to extract data not available in the most recent publication if needed. The following information was recorded for each included study:
- Citation;
* Language;
* Study aim;
* Study design;
* Setting;
* Study duration;
* Timing of data collection;
* Grade of renal trauma and instrument/system used;
* Type of renal trauma (blunt, penetrating, both);
* Total number of patients;
* Patients diagnosed with urinary extravasation;
* Patients treated with ureteral stenting for urinary extravasation;
* Management strategy used (other than ureteral stenting);
- Complications (if reported);

\section{Data synthesis}

Collected data, as well as the results from our literature search was used to identify knowledge gaps in incidence, diagnosis, and management of urinary extravasation after renal trauma. We calculated rates for ureteral stenting only when it was reported, because procedures such as nephrostomy tube and peri-renal drain placement, as well as open surgeries, were inconsistently reported, thus making it impossible to calculate meaningful rates of intervention for these procedures. Complication data was also rarely and inconsistently reported in individual studies and were not 
used for our analyses.

Incidence of urinary extravasation was calculated based on the extracted values for each study. The rates of urinary extravasation had to be reported differently based upon whether studies reported urinary extravasation rates in populations of grades III-V, IV-only, or IV-V. Rate of ureteral stenting was calculated in patients diagnosed with urinary extravasation. A meta-analysis of single sample binary proportions was performed using a random-effects model with the DerSimonian and Laird method (39). The pooled estimate was calculated after applying the Freeman-Tukey double arcsine transformation to stabilize the variances. Confidence intervals (CIs) were computed using the exact binomial (Clipper-Pearson) method (40). The meta-analysis was performed using the metaprop command (41) using STATA-15 statistical software (Stata corp., College Station, TX, USA).

\section{Search strategy}

Database: Ovid MEDLINE(R) Epub Ahead of Print, In-Process \& Other Non-Indexed Citations, Ovid MEDLINE(R) Daily and Ovid MEDLINE(R) (1946 to present).

Search strategy:

1. Acute Kidney Injury/or Kidney/in (41274)

2. (kidney or renal) adj3 (injury or injuries or wound? or trauma?). ti, ab,kw,kf. (30148)

3. (acute or major or sever \$) adj2 (kidney or renal) adj2 (injury or injuries or wound? or trauma?). ti,ab,kw,kf. (14181)

4. (blunt or bighgrade or bigh-grade or penetrat\$ or nonpenetrat $\$$ or non-penetrat\$) adj2 (kidney or renal). $t i, a b, k w, k f$. (643)

5. (Grade 3 or Grade III or Grade 4 or Grade IV or Grade 5 or Grade $V$ or $3 r d$ grade or 4th grade or 5 th grade) adj2 (kidney or renal). ti,ab,kf,kw. (308)

6. or/1-2,4-5 (Kidney Injury Set 1) (60921)

7. Kidney/ (253176)

8. (injury or injuries or trauma? or wound? or (Grade 3 or Grade III or Grade 4 or Grade IV or Grade 5 or Grade $V$ or $3 r d$ grade or 4 th grade or 5 th grade or highgrade or high grade)).ti. (357781)

9. ((acute or blunt or highgrade or bigh grade or major or non-penetrat\$ or penetrat $\$$ or sever $\$$ ) adj2 (injury or injuries or trauma?)). ti, ab,kw, kf. (103710)

10. ((Grade 3 or Grade III or Grade 4 or Grade IV or Grade 5 or Grade V or 3rd grade or 4th grade or 5 th grade) adj2 (injury or injuries or trauma? or wound?). $a b, k f, k w \cdot(785)$

11. (7 and (or/8-10)) not 6 (Kidney Injury—Set: 2) (1443)
12. extravasat\$.ti. (2536)

13. [Extravasat\$ adj2 (uret\$ or urol* or urin* or kidney or renal)]. ab,kf,kw. (538)

14. or/12-13 (Extravasation: Set 3) (2971)

15. (leakage or leak or leaking or leaks) adj2 (uret\$or urol* or urin* or kidney or renal). ti,ab,kf,kw. (3026)

16. (ureteral or urinar $\$$ or urolog $\$$ ) adj2 drain $\$$. ti,ab, $k w, k f$. (1011)

17. or/15-16 (Urinary Leak/Drain: Set 4) (4000)

18. Conservative Management/ (134)

19. (conservativ\$ or management). ti. (332107)

20. (conservat $\$$ adj2 (intervent $\$$ or manag $\$$ or therapy or therapies or treat\$). ab,kw, kf. (57151)

21. (non-surg\$ or nonsurg\$ or less invasiv\$ or initial\$ or non-operat $\$$ or nonoperat $\$$ or organ sparing) adj 3 (intervent $\$$ or manag $\$$ or treat $\$)$ ). ti,ab,kw. (73452)

22. $\{[($ revision or repeat $\$)$ adj 2 surg $\$]$ or reoperat $\$$. $t i, a b, k w, k f .(44871)$

23. Reoperation/ (74802)

24. or/18-23 (Management) (534573)

25. Nephrostomy, Percutaneous/ (4199)

26. (Nephrostom \$ or Nephrolithotomy or Nephrolithotomies). ti, ab,kw, kf. (6297)

27. or/25-26 (Nephrostomy) (7626)

28. [(uret\$ or urolog $\$$ or urin $\$)$ adj2 stent $\$]$. ti,ab, $k w, k f$. (3682)

29. (drain $\$$ adj3 tube?). ti,ab, $k w, k f$. (4973)

30. or/28-29 (Urin Stent or Drain) (8628)

31. Kidney/in and (Urogenital System/ or Urinary Bladder/ or Urinary Tract/) (238)

32. Kidney/ and (Urogenital System/in or Urinary Bladder/ in or Urinary Tract/in) (233)

33. (Kidney/ or Acute Kidney Injury/) and (Urogenital System/ or Urinary Bladder/ or Urinary Tract/) and ((injury or injuries? or wound? or trauma? or symptom?). ti,ab,kw,kf. or (injuries or therapy).fs.) (579)

34. (kidney.ti. or Kidney/ or Acute Kidney Injury/) and ("wounds and injuries"/ or Wounds, Penetrating/ or Wounds, Nonpenetrating/ or Wounds, Gunshot/ or Wounds, Stab/) (2024)

35. or/31-34 (Kidney and Urogenital \& Injury) (2489)

36. [extravasat $\$$ adj3 (kidney or renal)]. ti,ab,kw,kf. (Keyword) (112)

37. or/6,11 (Kidney Injury) (62364)

38. and/14,37 (Kidney Injury \& Extravasation: Results 1) (102)

39. (and/17,37) not 38 (Kidney Injury \& Urinary Leakage: Results 2) (106)

40. (and/24,37) not (or/38-39) (Kidney Injury o Management: Results 3) (2343)

41. (and/27,37) not (or/38-40) (Kidney Injury o 
Nephrostomy: Results 4) (216)

42. (and/30,37) not (or/38-41) (Kidney Injury \& Urinary Stent/Drain: Results 5) (62)

43. 35 not (or/38-42) (Kidney \& Urogenital etc. Injury: Results 6) (1967)

44. 36 not (or/38-43) (Results Set 7) (86)

45. animal/ not (animal/ and human/) (Animals MeSH) (4293926)

46. (animal? or beaver? or beef or bovine or breeding or bull or canine or castoris or cat or cattle or cats or chicken? or chimp $\$$ or cow or dog or dogs or equine or foal or foals or fish or insect? horse or horses or livestock or mice or monkey? or mouse or murine or plant or plants or pork or porcine or protozoa? or purebred or rat or rats or rodent? or sheep or thoroughbred).ti. or veterinar $\$$. $t i, a b, k w, k f, b w \cdot(2112064)$

47. or/45-46 [Animal Filter] (4775151)

48. (or/38-44) not 47 (All Results) (4616)

49. remove duplicates from 48 (4578)

\section{Data extraction sheet}

Scoping review title.

A. General information:

\begin{tabular}{|l|l|}
\hline 1. Date form completed (dd/mm/yyyy) & \\
\hline 2. Name of person extracting data & \\
\hline 3. Paper title & \\
\hline 4. First author-year & \\
\hline 5. Record number (From EndNote) & \\
\hline 6. Notes & \\
\hline
\end{tabular}

B. Eligibility:

A study is eligible if:

(I) Population study includes adults regardless of sex;

(II) The study clearly indicates the number of highgrade renal injuries (defined as AAST grades III-V or IV-V or IV or OIS equivalent);

(III) The study reports on number of patients diagnosed with urinary extravasation so an incidence of patients with urinary extravasation can be calculated (based on CT-scans, exclude if only IVP is used);

(IV) Inclusion for management part: the study mentions number of patients with urinary extravasation and the number who were managed with stenting (Note: only procedures specific for management of urinary extravasation will be included, and not those for bleeding or nonspecific).

Do not proceed if study excluded from review.

C. Population and setting:

\begin{tabular}{|l|l|}
\hline & Description \\
\hline Type of study (e.g., retrospective, prospective) & \\
\hline Study location and setting (city, country) & \\
\hline Start date -- End date & \\
\hline Duration of participation & \\
\hline Notes & \\
\hline
\end{tabular}

D. Participants:

\begin{tabular}{|l|l|}
\hline & Description \\
\hline Total No. of participants & \\
\hline Trauma types (blunt, penetrating, both) & \\
\hline $\begin{array}{l}\text { No. of HGRT (please indicate the grades } \\
\text { defined as high-grade) }\end{array}$ & \\
\hline $\begin{array}{l}\text { Grading system used (original 1989 AAST, } \\
\text { Revised 2011 AAST, Other- specify) }\end{array}$ & \\
\hline No. of renal injuries based on grades & \\
\hline AAST III & \\
\hline AAST IV & \\
\hline AAST V & \\
\hline No. patients with urinary extravasation & \\
\hline $\begin{array}{l}\text { Percentage of high grade renal trauma with } \\
\text { urinary extravasation (specify the denominator } \\
\text { and grades) }\end{array}$ & \\
\hline Notes & \\
\hline
\end{tabular}

E. Interventions \& outcomes for urinary extravasation (e.g., rhinorrhaphy or nephrectomy for bleeding is not relevant here):

\begin{tabular}{|l|l|}
\hline $\begin{array}{l}\text { Management options listed in the study for } \\
\text { urinary extravasation }\end{array}$ & Description \\
\hline No. of patients treated conservatively & \\
\hline $\begin{array}{l}\text { No. of patients received immediate/delayed } \\
\text { stenting }\end{array}$ & \\
\hline No. of patients with percutaneous nephrostomy & \\
\hline $\begin{array}{l}\text { No. of patients with peri-renal drain (if } \\
\text { mentioned) }\end{array}$ & \\
\hline $\begin{array}{l}\text { No. of patients needing renorrhaphy for urin. } \\
\text { extrav (if mentioned) }\end{array}$ & \\
\hline $\begin{array}{l}\text { No. of patients needing partial nephrectomy for } \\
\text { urin.extrav (if mentioned) }\end{array}$ & \\
\hline $\begin{array}{l}\text { No. of patients needing nephrectomy for urin. } \\
\text { extrav (if mentioned) }\end{array}$ & \\
\hline $\begin{array}{l}\text { Notes (please explain how the study reports } \\
\text { extravasation and its management) }\end{array}$ & \\
\hline
\end{tabular}


Complications and follow-up specific for urinary extravasation:

\begin{tabular}{|l|l|}
\hline & Description \\
\hline No. of urinomas (and\%) & \\
\hline No. of other complications & \\
\hline Notes: & \\
\hline
\end{tabular}

\section{Final decision}

Please indicate if this study will be included in the final table for the manuscript.

Explain the reason for exclusion after full-review.

\section{References}

38. Arksey H, O'Malley L. Scoping studies: towards a methodological framework. Int J Soc Res Methodol 2002;8:19-32.

39. DerSimonian R, Laird N. Meta-analysis in clinical trials revisited. Contemp Clin Trials 2015;45:139-45.

40. Newcombe RG. Two-sided confidence intervals for the single proportion: comparison of seven methods. Stat Med 1998;17:857-72.

41. Nyaga VN, Arbyn M, Aerts M. Metaprop: a Stata command to perform meta-analysis of binomial data. Arch Public Health 2014;72:39. 